\title{
HOT-WATER DRILLING ON CRARY ICE RISE, ANTARCTICA
}

\section{(Abstract)}

\author{
by \\ B. Koci
}

(Polar Ice Coring Office, University of Nebraska-Lincoln, Lincoln, NB 68588-0200, U.S.A.)

and

R. Bindschadler

(NASA Goddard Space Flight Center, Greenbelt, MD 20772, U.S.A.)

\begin{abstract}
A new hot-water drill was used successfully to drill two holes to the bed of Crary Ice Rise. Hole depths were 370 and $480 \mathrm{~m}$. Average drilling rates of $0.4-0.5 \mathrm{~m} / \mathrm{min}$ were employed to ensure a large hole diameter. Instrumentation on the drill stem provided data on inclination (two axis), hole diameter, water depth, and water temperature near the nozzle opening and at two other points along the drill stem. These data were available for review during the drilling, as well as being recorded on diskette by a personal computer. Water in the system was recirculated by means of a pump, suspended $40 \mathrm{~m}$ down the hole, which kept a 500 gallon tank on the surface filled. Water was heated to $90^{\circ} \mathrm{C}$ by a set of six standard car-wash heaters.

In the first hole $(370 \mathrm{~m})$, the bed was sensed by the simultaneous occurrence of three events: a decrease in tension in the drilling hose, an increase in the water pressure of the drilling system (normally 180 psi), and an
\end{abstract}

indicated increase in tilt of the inclinometers on the drill stem.

In the second hole $(480 \mathrm{~m})$, a similar coincidence of events occurred but the drill remained at this level for approximately $1 \mathrm{~h}$ before being raised to the surface. When the drill was returned to the surface, the drill stem was coated with a thick mud, and a rock and a clast were lodged in the caliper arms of the drill.

The rock is strongly faceted, igneous in composition, and appears to be a member of a lodgement till. Striations cannot be seen; scanning electron microscopy is planned to search for microscopic striations. The loose sedimentary material contains a large amount of gravel. This material is rich in diatoms. R. Scherer (personal communication) has identified the youngest diatoms in the sediment to be of Upper Miocene age. The clast seems to be composed of sedimentaty material and may be more representative of how this material exists in situ beneath Crary Ice Rise.

\section{A PHENOMENOLOGICAL CONSTITUTIVE EQUATION}

\section{(Abstract)}

\author{
by
}

R.C. Lile

(Department of Meteorology, University of Melbourne, Parkville, Victoria 3052, Australia)

When the Sinha equation is constrained to describe laboratory ice in uniaxial compression, it degenerates to the
Andrade form, a modification of which is shown to offer a good fit to data extending into the tertiary creep stage.

\section{RELATION BETWEEN WATER INPUT, BASAL WATER PRESSURE, AND SLIDING OF COLUMBIA GLACIER, ALASKA, U.S.A.}

\section{(Abstract)}

by

Mark F. Meier
The University of Colorado and Caltech, together with personnel from the U.S. Geological Survey and the University of Washington, drilled through Columbia Glacier at two locations (ice thickness 975 and $560 \mathrm{~m}$ ) $9 \mathrm{~km}$ apart in the summer of 1987. Fluctuations in basal water pressure, water input as rain or ice melt, and surface-ice velocities were measured at short time intervals continuously during July and August. Surface velocities are essentially equal to sliding velocities in these areas of rapid flow $(3-10 \mathrm{~m} / \mathrm{d}$ ) and high basal water pressure (nearly equal to flotation). 